\title{
The role of knowledge-oriented leadership in knowledge management and innovation
}

\author{
Abdolreza Sadeghi ${ }^{a *}$ and Fereshteh Mostafavi Rad ${ }^{\mathrm{b}}$
}

${ }^{a}$ Head Manager of the Office of Planning, Renovating and Administrative Reform of the Governorate of Fars ${ }^{b}$ Assistant Professor, Sepidan Branch, Islamic Azad University, Sepidan, Iran

\section{H R O N I C L E}

\section{Article history:}

Received: November 26, 2017

Received in revised format: November 26, 2017

Accepted: January 27, 2018

Available online:

January 29, 2018

\section{Keywords:}

Knowledge based leadership

Knowledge management

Innovation performance

\section{A B S T R A C T}

\begin{abstract}
Innovation is one of the key factors distinguishing organizations from competitors in today's highly competitive markets. Therefore, improving innovative performance is critical for creating competitive advantage. On the other hand, availability of information and knowledge can be defined as one the best ways to increase the innovation ability of organizations. Many theorists as well as practitioners emphasize on knowledge management as an enabler in enhancing organizational innovation. Hence, This study is carried out in the Fars governor in Iran during the year of 2017 to investigate the relationship between the knowledge-based leadership and knowledge management and innovation performance. This study is descriptive / survey and the data collection is a cross-sectional and data questionnaire is used to collect the required data. Data analysis and hypotheses testing have indicated a significant relationship between knowledge-based leadership and knowledge management and innovation performance in Fars governor. The results also suggest a relationship between knowledge-based leadership and the knowledge management activities with a coefficient of 0.97 . In addition, There is also a positive and meaningful relationship between knowledge management and innovation performance with a coefficient of 0.73 and between knowledge-based leadership and innovation performance with a coefficient of 0.73 . The results also led to the existence of a relationship between knowledge based leadership, knowledge management practices and innovation performance with a coefficient of 0.7081 .
\end{abstract}

\section{Introduction}

The rapid pace of development of new technologies and digital communications has led to an increase in the importance of knowledge management (KM) as a vital source for gaining competitive advantage (Obeidat \& Abdallah, 2014). Thus, the researchers have come to the agreement that knowledge-based management is critical for the success of the organizations, even if it's not easy to reach. Based on the principles of knowledge management, all organizations are involved in the development and implementation of knowledge management to improve the efficiency of business processes, increase the cost and quality of their services, and find solutions and new products for their customers. In the present days, knowledge and information management have become a solid ground for survival in dynamic

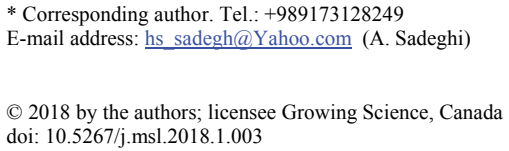


and innovative organizations, and even the ability to compete in markets and commerce depends on the acquisition, development, and updating of individual and organizational knowledge to the extent that knowledge is considered as an essential part of the capital (Hansen et al., 1999). Therefore, vigilant management is committed to confront uncertain factors, maintain a position and promote creativity and innovation for expanding competitive supply (Singh, 2008).

Managing organizations, based on superior knowledge, can make more meaningful decisions on important issues and improve knowledge-based practices (Ndlela, 2010). Therefore, knowledge management is considered to be more important than the knowledge itself, and organizations seek to clarify how individual and organizational information and knowledge are transformed into individual and group knowledge and skills. Successful managers outperform others to create an environment without fear and trust that members are willing to share knowledge with each other, an environment that maximizes knowledge creation and drives knowledge into innovation (Donate \& de Pablo, 2015). In fact, knowledge management is considered as a way to improve the company's innovation capabilities (Kanter, 1984). The Austrian economist, Schumpeter (2017), has defined innovation as creating a new business using one of the new materials or components, presenting new processes, creating new markets or employing new organizational organizations. In his definition of innovation, Moss-Kanter (1983) emphasizes the process and considers innovation to be the process of exploring any new and useful idea to solve the problem, and believes that innovation involves the formulation of ideas, acceptance and implementation of new ideas in the process, products and services.

On the other hand, one of the factors influencing knowledge management is knowledge-based leadership (Yahya \& Goh, 2002). Leadership behavior is one of the important factors that greatly influences the direction and effectiveness of knowledge management in the organizations. In fact, the role of leaders in knowledge management in an organization is important. Because today's leaders have a significant position to influence their organizations. Hence, knowledge-based leadership has increasingly been recognized as an essential element for the organizations to enhance knowledge management. On the other hand, many scholars have emphasized the lack of leadership support in the failure of many KM projects (Taherparvar et al., 2014).

Nevertheless, it should be acknowledged that the governorates as one of the most active organizations aimed at implementing the public policy of the state within the country by coordinating various activities of state and local institutions in different provinces, towns, districts, villages and villages. Regarding the issues in the Fars Governorate, located in province of Fars/Iran, such as the optimization of the information process, the organization has focused on organizing the processes within the organization with the aim of eliminating cases and bureaucracy and increasing the speed and accuracy of the affairs, and therefore the importance of the leadership of the organization. The objective of the organization is to manage knowledge and improve innovation.

On the other hand, previous studies in this field have identified the relationship between knowledgebased leadership and knowledge management and innovation practices. However, these studies have investigated the relationship between leadership and the specific actions of knowledge management, and there were some relationships between the general conditions of leadership and the actions of knowledge management and innovation. Therefore, in view of the importance of knowledge-based leadership in the provincial governorate of Fars, as well as the cornerstone of the scientific vacuum described in this area, the present study aims to study the relationship between knowledge-based leadership, knowledge management and innovation in the Fars Governorate in Iran. 


\section{Literature review}

\subsection{Knowledge management}

Although the debate on this topic had already started, the term "knowledge management" entered the management literature in the early 1990s. Historically, three generations of knowledge management can be distinguished from one another. The period of 1990-1995 can be the first generation of knowledge management. In this period, most efforts focused on defining knowledge management, examining its potential benefits to organizations, and designing specific knowledge management projects. The second generation of knowledge management emerged around 1996 by creating new jobs for knowledge management and senior managers of knowledge. In this period, different sources of knowledge management were combined and these issues quickly entered into the daily routine issues of organizations (Yew Wong, 2005). In this generation, research in the field of knowledge management focuses on issues such as knowledge definitions, business philosophy, systems, frameworks, operations, and applications. The result of this view is the third generation of knowledge management, which is now emerging with new methods and outcomes. One of the differences of this generation with the previous generations is the degree of integrity or integration of knowledge management with the philosophy, strategy, goals, activities, systems and procedures of the organization, and how to manage knowledge conversion. It has become part of the daily lives and motivation of the staff. It seems that the third generation focuses on the connection between science and action (Lakshman \& Parente, 2008; Paraponaris, 2003).

Although the concept of KM is the subject of today's management meetings, it is not new. Traditionally, family business owners have long transferred their knowledge to their children, but for many organizations and their executives, the concept of KM has only been considered from a short time ago. Gómez-Pérez et al. (2006) believes that knowledge management is the accumulation of knowledge, rational capabilities, and the experiences of individuals in an organization and the ability to retrieve them as an organizational capital. Newman (1997) believes that knowledge management was a collection of phenomena that involved the creation, dissemination and application of subjective and objective knowledge in an organization. As the knowledge of an organization contributes to its increasing competition and improves decision-making, the acquisition, sharing, maintenance and reuse of organizational knowledge have become vital for many organizations. The process of leveraging the knowledge of an organization as a means of achieving innovation in processes and products, services, effective decision making, and organizational compliance with the environment refers to knowledge management that leads to organizational creativity. Since knowledge has two implicit and explicit dimensions, its management is also a combination of data and information processing, the capability of mixed information technologies with the ability to innovate and creativity of individuals.

\subsubsection{Knowledge based leadership}

Although until recently the discussion about KM was an interesting topic in the focus of thinking, today knowledge-based leadership has attracted the attention of active thinkers in the realm of management. Leadership theories and research in KM has begun (Crawford, 2005). Lina and Aasta (2012) argue that organizations can be effective in knowledge transfer processes. Lackchmann and Parent (2008) state that knowledge-based leadership plays an important role in enhancing organizational knowledge, attracting and transferring it, organizing knowledge, creating insight and managing knowledge and information. Knowledge leadership is considered to be the stimulus of the relationship between the components of intellectual capital management of the organization. Contemporary management scholars often emphasize the effectiveness of the acquisition, development and deployment of knowledge, and believe that the acquisition of new knowledge depends on the transformation of the organizations and the leadership activities and adapts to changing organizational conditions. One of the variables that knowledge-based leadership influences on is the ability to attract knowledge. 
Cohen and Levintel (1990) introduce absorption capacity as a macroeconomic concept into the field of organizational theories, identifying it as the ability of an organization to recognize the value of new information from external sources, simulating and applying it for commercial purposes. One of the main reasons on why organizations tend to point out the issue of the knowledge based leadership is that this kind of leadership leads to more productivity than human capital, identifying deficiencies in organizational knowledge, more efficient and effective staffing, product delivery and more value added services, customer and employee satisfaction, preventing repetitive mistakes, reducing rework, saving time, updating and developing creativity, encouraging and innovating, organizing and expanding the knowledge flow from manufacturer to recipient and facilitating information sharing among employees (Yang et al., 2014). The organization's ability to cope with the inflation phenomenon increases information. It improves the quality of customer service and, through increasing the level of awareness of the organization, it helps the organization avoid competing against solutions, products and performance of competing organizations (Nam Nguyen \& Mohamed, 2011).

\subsection{Organizational innovation}

Innovation is one of the management concepts that has a close relationship with enterprise entrepreneurship and it cannot be ruled out when defining entrepreneurship. Even if the existing research into organizational innovation has taken another route due to a number of considerations, it must still be remembered that these two concepts have a very important historical and common history. This background goes back to the wider scope of the meaning of innovation, and this is what can be called the concept of innovation from the perspective of Schumpeter (2017). Drucker (1998) also considers innovation as a specialty for entrepreneurship. According to him, innovation is distinguished between entrepreneurial affairs and management issues. In fact, we can say that the concept of innovation in Schumpeter's view distinguishes entrepreneurship behavior from other managers and, as a result, makes entrepreneurship and innovation inseparable. Despite these similarities, in this article there is a distinction between these two concepts. One important reason is the difficulty of providing a common and accepted definition of innovation. Gopalkrishnan and Damanpour (1997) examine the concept of innovation in a variety of scientific fields such as economics, organizational sociology, and technology management. They came to the conclusion that in all these areas, innovation had been considered as a tool for adapting to changes and making new things. But the most important thing was that they observed that researchers used different concepts in every field of innovation, as well as quite different views on their impact on industry, productivity, life, growth and organizational performance. These differences focused on how to focus on the innovation process, the field of study, and the type of innovation. Choi and Lee (2002) did the same for such a study, and found that innovation was very complex in nature and depends on the field of activity. Therefore, one can conclude that innovation is a broad concept that has different meanings in different theoretical fields. It might be best to look at innovation from the perspective of more classical terms, such as commercializing a new invention a product or a new technology. Nevertheless, despite the use of such a broad definition of organizational innovation, the distinction made above is still valid. It should be noted that both of these concepts have similarities in relying on the concept of novelty, but moreover, organizational innovation focuses on the production of the product (Nam Nguyen \& Mohamed, 2011). While organizational entrepreneurship is more oriented towards newly emerging orientations, its main purpose is to deviate from the conventional methods of doing business in the organization. Now, this may lead to the production of new products. In addition, organizational entrepreneurship may include activities whose main purpose is to deviate from the traditional methods of doing business in the organization with the aim of discovering new ways. This can be done by changing the strategies and methods of organizing risk taking, going ahead and competing, in which case it can be said that organizational innovation is a subset of enterprise-wide entrepreneurship. Unlike organizational innovation, enterprise entrepreneurship is an entrepreneurial approach in the units that are currently engaged. So it is within the whole range of entrepreneurial research. This is a good idea for the development of this subcategory. Perhaps it is a good idea to note that the use of the term "entrepreneurial enterprise" is very suitable because (contrary to the terms of 
innovation, etc.) its limitations are well-defined with other similar concepts. Therefore, the use of the term "entrepreneurial enterprise" is a more precise method for describing innovation-oriented entrepreneurship. It should be noted that Schumpeter's hypothesis of creative destruction has led to a great deal of development in the concept of enterprise entrepreneurship. However, we do not intend to divide the concept of innovation into Schumpeter-based innovation on the one hand, which is non-persistent and revolutionary, and to bring on-going innovation (on the other hand). Because, when discussing the organization, there is no need for innovation to be categorized gradually or suddenly. An important issue is the distinction between innovation in product production and innovation in the production process.

\section{The proposed method}

The present study aims to explain the relationship between knowledge leadership and knowledge management and innovation performance in the governorate of the province Fars in Iran the model originally proposed by Donate and de Pablo (2015). In this study, knowledge leadership is an independent variable, KM functions in the dimensions of knowledge transfer, knowledge management and the use of knowledge management are considered as intermediary variables, and finally innovation in the process and services are considered as dependent variables. According to the principles of KM, all organizations will develop and implement knowledge management to improve the efficiency of business processes, increase the productivity and quality of their services, and find new solutions and products for their customers. One of the factors influencing innovation in services and processes is the knowledge management and knowledge management functions.

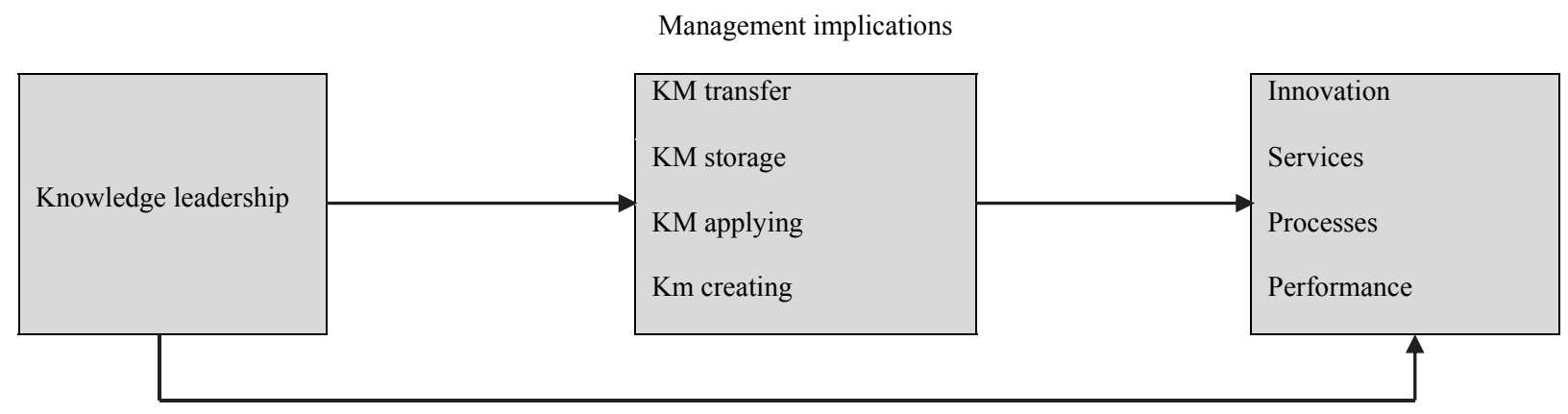

Fig. 1. The proposed study of this paper

Main hypothesis: There is a relationship between knowledge-based leadership and knowledge management and innovation performance in the governorate of Fars.

\section{Sub-hypotheses}

1. There is a relationship between knowledge-based leadership and knowledge management practices in the governorate of Fars.

2. There is a relationship between the functions of knowledge management and the performance of innovation in the governorate of Fars.

3. There is a relationship between knowledge-based leadership and innovation performance in the governorate of Fars.

4. There is a relationship between knowledge-based leadership through the functions of knowledge management and innovation performance in the governorate of Fars. 
This research can be considered as a descriptive and survey-based research. The present research is conducted in a natural environment with minimal intervention by the researcher. The statistical population of this research is made up of 500 employees by all the staff of Fars Governorate in Fars Province/ Iran. The sampling method is relative class and the sample size is determined to be 207 people using Morgan table. In this research, a questionnaire including knowledge-based leadership questionnaire, knowledge management and innovation was used to collect the necessary data. Table 1 summarizes the profile of the questionnaire used. In this study, we used SPSS software to analyze the collected data using AMOS software and to measure the reliability of the questionnaire, we used Pearson correlation and structural equations to analyze the data in this study.

According to Table 1, the process innovation variable has the highest mean (3.72) and knowledge transfer (3.11) has the lowest average. The observed skewness values for research variables are in the range $(-2,2)$. In other words, the slope of the variable is normal and its distribution is symmetric. The amount of elongation of the variables is also in the range $(-2,2)$. This indicates that the distribution of variables is normal.

Table 1

Basic statistics on the survey

\begin{tabular}{lcccccc}
\hline Variable & $\begin{array}{c}\text { Knowledge } \\
\text { based } \\
\text { leadership }\end{array}$ & $\begin{array}{c}\text { Knowledge } \\
\text { management }\end{array}$ & $\begin{array}{c}\text { KM } \\
\text { transfer }\end{array}$ & $\begin{array}{c}\text { KM } \\
\text { storage }\end{array}$ & $\begin{array}{c}\text { Km } \\
\text { implication }\end{array}$ & $\begin{array}{c}\text { Innovation } \\
\text { innovation }\end{array}$ \\
innovation
\end{tabular}

In order to determine which indicators are acceptable for the measurement in the model. First, the individual measurement patterns were analyzed and the general indexes of pattern matching were used for the measurement models (confirmatory factor analysis). To test the hypotheses, structural equations modeling has been used to determine the possibility of the effect of factors on each other. This statistical test is analyzed using the AMOS software. In Fig. 2, the standard and significant values of the final model of research have been shown.

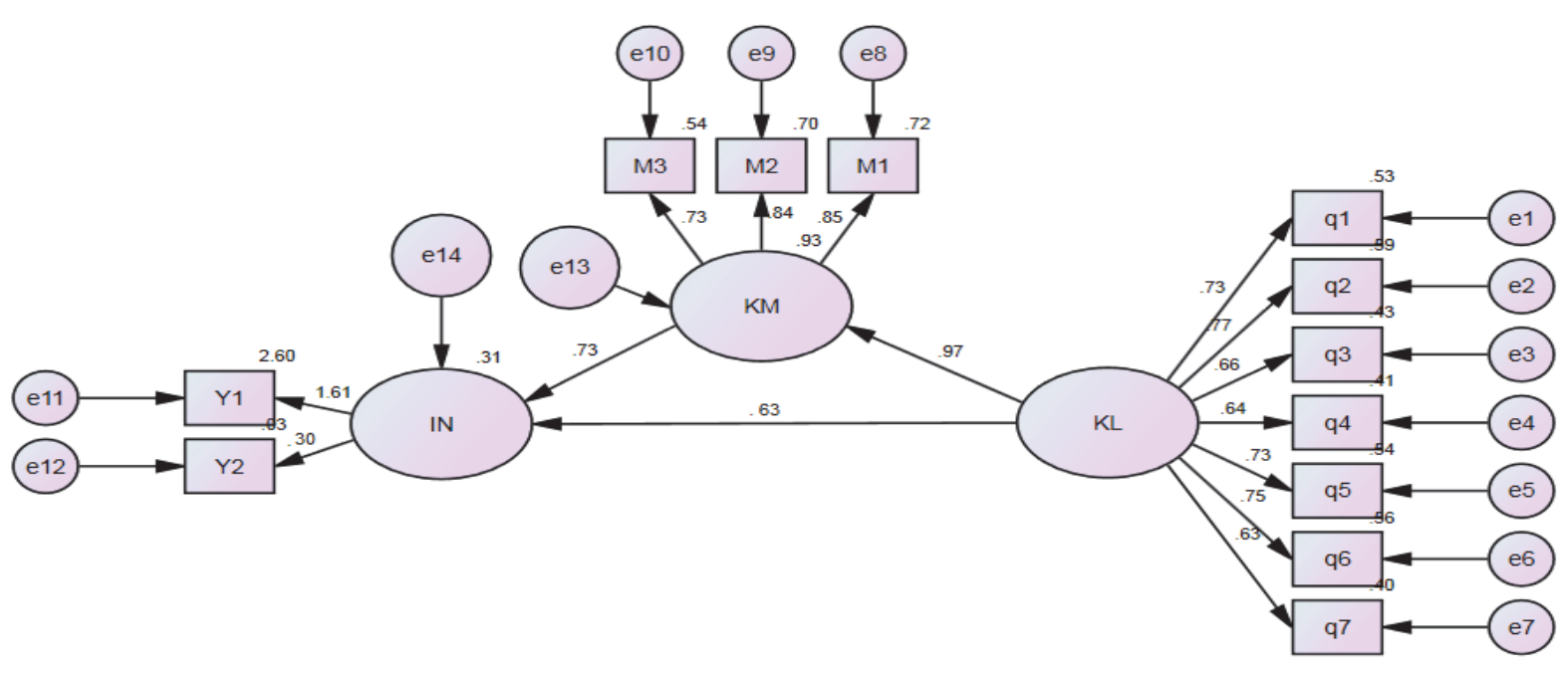

Fig. 2. The results of the implementation of the structural equation modeling 
In this section, the general indicators of variable fit are shown. Table 2 shows the goodness of the fitting of the structural equation model and Table 3 shows the results of the model test

\section{Table 2}

The results of the statistical tests

\begin{tabular}{rrrrrrrr}
\hline CMIN/DF & NFI & GFI & RMR & IFI & CFI & RMSEA \\
\hline 2.827 & 0.90 & 0.97 & 0.04 & 0.90 & 0.90 & 0.06 \\
\hline
\end{tabular}

Regarding the results of the fittest test, the research model shows that all fitting indexes of the model represent the proper fitness of the model, as well as testing the model assumptions that all the assumptions of the model have been confirmed and it can be concluded that the model conceptualization in society has been reviewed and approved.

Table 3

The results of testing the hypotheses of the survey

\begin{tabular}{lllccccr}
\hline Hypothesis & \multicolumn{2}{c}{ Hypothesis } & Critical & P & Regression & Result \\
\hline Main hypothesis & Knowledge leadership & $\rightarrow$ & Innovation performance & 4.151 & 0.001 & $0.97^{*}-0.73=0.7081$ & Confirmed \\
First hypothesis & Knowledge leadership & $\rightarrow$ & $\begin{array}{c}\text { KM management } \\
\text { functions }\end{array}$ & 9.588 & 0.001 & 0.97 & Confirmed \\
$\begin{array}{l}\text { Second } \\
\text { hypothesis }\end{array}$ & $\begin{array}{l}\text { KM management } \\
\text { functions }\end{array}$ & $\rightarrow$ & Innovation performance & 2.459 & 0.001 & 0.73 & Confirmed \\
Third hypothesis & Knowledge leadership & $\rightarrow$ & Innovation performance & 2.683 & 0.001 & 0.63 & Confirmed \\
Fourth hypothesis & Knowledge leadership & $\rightarrow$ & Innovation performance & 4.151 & 0.001 & $0.97 *-0.73=0.7081$ & Confirmed \\
\hline
\end{tabular}

\section{Management implications}

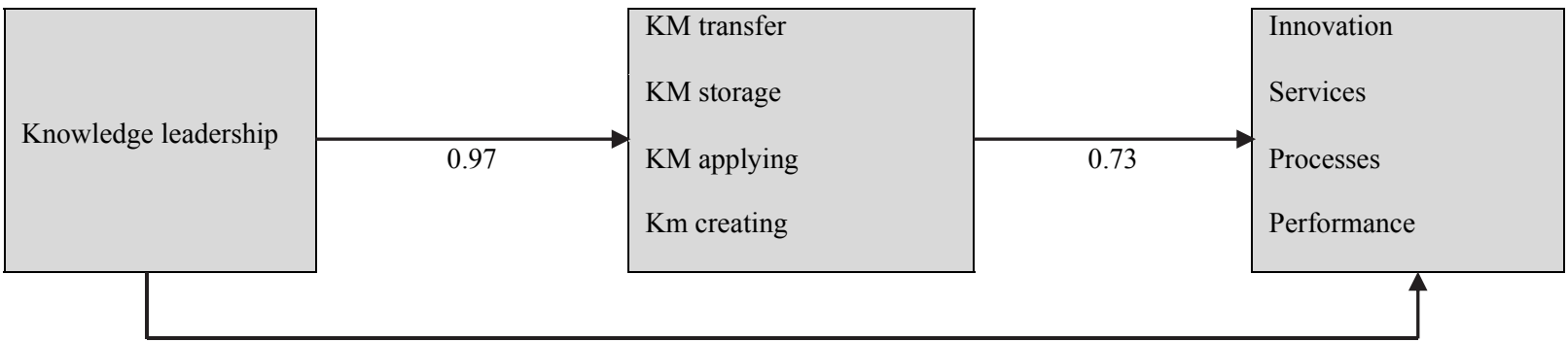

Fig. 3. The results of the proposed study of this paper

\section{Conclusion}

Different companies worldwide develop and implement knowledge management innovations to improve their processes, productivities and quality of their services, and provide solutions and products/New services for customers. The KM leadership suggests a significant change in the challenges faced by managers in recent years. In addition, in the field of technology, innovation is usually a direct consequence of the effectiveness of knowledge management and one of the main goals of knowledgeproducing companies to pursuit of competitive advantages. Today, the art of leadership and management of organizations is becoming the art of knowledge management, which means that a manager simply does not manage individuals but manages the knowledge and leadership means to provide the right conditions for the production of knowledge. Leadership is one of the basic requirements for the activities of many of today's organizations; it also plays a key role for the success of KM. On the other hand, despite the fact that choosing the appropriate leadership style can act as an empowering agent of knowledge management, neglecting this issue and the mismatch of leadership style in the organization, with the vital principles of knowledge management, can lead to unpleasant consequences for the firms. Knowledge-based leadership and proper knowledge management through the production, maintenance and storage of knowledge can improve organizational performance at all levels of the organizations. 
The results of the data analysis in this study have shown that the relationships between knowledgebased leadership variables, knowledge management and innovative practices have been confirmed, and there was a significant correlation between all variables. Also, after examining the relationship between knowledge-based leadership and knowledge management and innovation performance in the governorate of Fars, the main hypothesis was confirmed. From the perspective of respondents, the variable of knowledge-based leadership and knowledge management were the first variables in this part. The hypothesis is confirmed and maintained the strongest meaningful relationship with the variable of knowledge management. From the perspective of variable respondents, innovation performance is the second variable introduced in this part of the hypothesis and had a meaningful relationship with the leadership variable and knowledge management. The results of research data analysis also indicated that the effect of knowledge-led leadership and knowledge management and innovation performance had a coefficient of 0.7081 , with a critical value of $4.151>1.96$. It can therefore be stated that the null hypothesis could be rejected with $95 \%$ confidence. In other words, knowledge-based leadership and knowledge management and innovation performance had a statistically significant effect. Therefore, this hypothesis was accepted and there is a relationship between knowledge-based leadership and

knowledge management and innovation performance in the governorate of Fars. The test result of this hypothesis was consistent with the results of study proposed by Yang et al. (2014) and Donate and de Pablo (2015).

Considering the results obtained in the main hypothesis and confirming the hypothesis that there was a relationship between knowledge-based leadership and knowledge management and innovation performance in the governorate of Fars, it is suggested that managers of organizations emphasize knowledge acquisition and production. It also encourages employees to influence the production, storage, and transfer of tacit and explicit knowledge by encouraging employees to document their skills in information systems and facilitate the transfer of information to other parts of the organization, also through support and the process of sharing knowledge in the organization, and removing the barriers to sharing knowledge in the organization.

Also, according to the results obtained in the first hypothesis and the confirmation of the hypothesis there is a relationship between knowledge leadership and knowledge management functions in the governorate of Fars. It is suggested to provide an appropriate atmosphere among managers and staff to discuss working methods and practices, and to facilitate and justify the issues of internal decision making. Also, according to the results obtained in the second hypothesis, and the confirmation of the hypothesis that there was a relationship between the functions of knowledge management and the performance of innovation in the governorate of Fars, it is suggested that attention be paid to staffing issues in order to promote knowledge management and innovative performance by holding various training courses and workshops. On the other hand, according to the results obtained in the third hypothesis and confirmation of the hypothesis there was a relationship between knowledge leadership and innovation performance in the governorate of Fars; it is suggested that the organization initially create the behavioral and cultural platforms for innovation; and only in such enabling environments will the organization be able to innovate in its proper innovative manner. Also, according to the results of the fourth hypothesis and the confirmation of the hypothesis there was a relationship between knowledge-based leadership through the functions of knowledge management and innovation performance in the governorate of Fars and it is suggested that, the present knowledge of leadership and its management are considered as an important and priority goal. The organization should invest in different flows of organizational knowledge and leadership in accordance with its priority in terms of speed and quality of innovation and service and operational performance.

\section{Acknowledgement}

The authors would like to thank the anonymous referees for constructive comments on earlier version of this paper. 


\section{References}

Choi, B., \& Lee, H. (2002). Knowledge management strategy and its link to knowledge creation process. Expert Systems with Applications, 23(3), 173-187.

Crawford, C. B. (2005). Effects of transformational leadership and organizational position on knowledge management. Journal of Knowledge Management, 9(6), 6-16.

Donate, M. J., \& de Pablo, J. D. S. (2015). The role of knowledge-oriented leadership in knowledge management practices and innovation. Journal of Business Research, 68(2), 360-370.

Drucker, P. F. (1998). Harvard business review on knowledge management. Harvard Business Press.

Gómez-Pérez, A., Fernández-López, M., \& Corcho, O. (2006). Ontological Engineering: with examples from the areas of Knowledge Management, e-Commerce and the Semantic Web. Springer Science \& Business Media.

Gopalakrishnan, S., \& Damanpour, F. (1997). A review of innovation research in economics, sociology and technology management. Omega, 25(1), 15-28.

Hansen, M. T., Nohria, N., \& Tierney, T. (1999). What's your strategy for managing knowledge. The knowledge management yearbook 2000-2001, 1-10.

Kanter, R. M. (1984). Change masters. Simon and Schuster.

Lakshman, C., \& Parente, R. C. (2008). Supplier-focused knowledge management in the automobile industry and its implications for product performance. Journal of Management Studies, 45(2), 317342.

Moss-Kanter, R. (1983). The change masters: Innovation for productivity in the American corporation. NY: Simon and Schuster.

Nam Nguyen, H., \& Mohamed, S. (2011). Leadership behaviors, organizational culture and knowledge management practices: An empirical investigation. Journal of Management Development, 30(2), 206-221.

Ndlela, M. N. (2010). Knowledge Management in the Public Sector: Communication Issues and Challenges at Local Government Level. In Proceedings of the 11th European Conference on Knowledge Management Vols 1 and (Vol. 2, pp. 711-716).

Newman, V. (1997). Redefining knowledge management to deliver competitive advantage. Journal of knowledge management, 1(2), 123-128.

Obeidat, B. Y., \& Abdallah, A. B. (2014). The relationships among human resource management practices, organizational commitment, and knowledge management processes: A structural equation modeling approach. International Journal of Business and Management, 9(3), 9.

Paraponaris, C. (2003). Third generation R\&D and strategies for knowledge management. Journal of Knowledge Management, 7(5), 96-106.

Schumpeter, J. A. (2017). Essays: on entrepreneurs, innovations, business cycles and the evolution of capitalism. Routledge.

Singh, S. K. (2008). Role of leadership in knowledge management: a study. Journal of knowledge management, 12(4), 3-15.

Taherparvar, N., Esmaeilpour, R., \& Dostar, M. (2014). Customer knowledge management, innovation capability and business performance: a case study of the banking industry. Journal of knowledge management, 18(3), 591-610.

Yahya, S., \& Goh, W. K. (2002). Managing human resources toward achieving knowledge management. Journal of Knowledge Management, 6(5), 457-468.

Yang, L. R., Huang, C. F., \& Hsu, T. J. (2014). Knowledge leadership to improve project and organizational performance. International Journal of Project Management, 32(1), 40-53.

Yew Wong, K. (2005). Critical success factors for implementing knowledge management in small and medium enterprises. Industrial Management \& Data systems, 105(3), 261-279. 


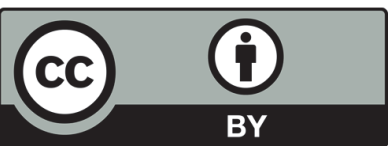

(C) 2018 by the authors; licensee Growing Science, Canada. This is an open access article distributed under the terms and conditions of the Creative Commons Attribution (CC-BY) license (http://creativecommons.org/licenses/by/4.0/). 